\title{
Correction to: TPF in England
}

\section{Correction to:}

\section{Chapter 2 in: B. Zhang, Third Party Funding for Dispute}

Resolution, https://doi.org/10.1007/978-981-16-1095-0_2

The original version of the book was inadvertently published with incorrect title for Chapter 2. The book has been updated with the change. 